\title{
CONVENCIONALIZAÇÃO OU ALTERNATIVIDADE: OS DOIS LADOS DA MESMA MOEDA
}

\section{CONVENTIONALIZATION OR ALTERNATIVITY: THE TWO SIDES OF THE SAME COIN}

Camila Lago Braga*

LE VELLY, Ronan. Sociologie des systèmes alimentaire alternatifs. Une promesse de différence. Paris: Presse des Mines, Collection Sciences sociales, 2017. 193 p.

Recentemente, observamos uma tendência à valorização do que se convencionou chamar de Sistemas Alimentares Alternativos (SAA) ou Redes Agroalimentares Alternativas (RAA), cuja gênese das pesquisas data dos anos 1990 a 2000. Estes estudos foram impulsionados, principalmente, pela crise dos Sistemas Alimentares Convencionais (SAC), decorrente dos constantes "escândalos alimentares", que colocaram em cheque a qualidade dos produtos advindos desse modelo dominante de produção e consumo (GOODMAN, 1999). Assim, nas mais diversas pesquisas sobre o tema, experiências heterogêneas tais como a agricultura orgânica, comércio justo e circuitos curtos de comercialização têm sido apreendidos como tipos de SAA. Portanto, vários estudos se concentraram na contribuição dessas abordagens como um "novo paradigma de desenvolvimento rural", voltado para sua capacidade de "reincorporar" a agricultura e a alimentação nos países em desenvolvimento, sobretudo a partir dos processos naturais, heranças culturais ou relações sociais (PLOEG et al., 2000). Neste sentido, os SAAs são vistos como espaços de "autonomia" ou "resistência" ao modelo

* Doutoranda pelo Programa de Pós-Graduação em Desenvolvimento Rural da Universidade Federal do Rio Grande do Sul - UFRGS - (Porto Alegre/RS/BR). E-mail: camila.lago.braga@gmail.com 
globalizante vigente (GOODMAN, 2009).

Diante dessa problemática, Ronan Le Velly, atualmente professor de sociologia na Universidade de Montpellier SupAgro, e membro da Unidade Conjunta de Pesquisa (UMR) "Inovação e Desenvolvimento na Agricultura e Alimentação”, apresenta em Sociologia dos Sistemas Alimentares Alternativos: uma promessa de diferença, sua mais recente obra, publicada em 2017, uma análise sociológica dos projetos que inspiraram os Sistemas Alimentares Alternativos (SAAs) e as atividades regulatórias que lhes deram origem.

Esta obra se insere no bojo de importantes debates que passaram a questionar os estudos que identificavam uma trajetória de convencionalização da agricultura alternativa, marcadamente pela sua incorporação ao setor da agricultura industrial, através de uma interação entre o alternativo e o modelo alimentar dominante, provocando uma perda da associação com o local e com as práticas tradicionais (POMÉON et al, 2017). Neste sentido, o autor se propõe a estabelecer uma baliza crítica ao debate a respeito dos SAAs e seus quadros teóricos, apresentados como uma promessa de diferença frente ao modelo convencional.

Através de diferentes pesquisas de campo e de estudos de caso, Le Velly discute as experiências de comércio justo, agricultura orgânica e circuitos curtos de comercialização, tencionando compreender as reorganizações iniciadas, para colocá-las em prática, e também a natureza desigual e transformadora dos arranjos existentes. Se propondo a estabelecer um quadro original de análise, constrói seu argumento inspirado na sociologia da ação organizada, com Jean Daniel Reynaud ou Erhard Friedberg, e na sociologia dos agenciamentos mercantis derivados da teoria do ator-rede, de Bruno
Latour e Michel Callon, analisadas em torno da noção de "atividades de regulação".

Estruturada em seis capítulos, a obra traz inicialmente uma apresentação dos problemas específicos ligados aos estudos dos Sistemas Alimentares Alternativos, bem como o quadro de análise elaborado para respondê-lo. Assim, no Capítulo 1 "Como estudar os sistemas alimentares alternativos?", Le Velly parte de uma revisão de literatura de obras produzidas por autores europeus e norte-americanos, a fim de trazer uma crítica ao uso do conceito dos SAAs, vistos a partir de um pensamento binário que coloca "alternativo" e "convencional" como mundos opostos, ou a partir de um dualismo entre pequeno/alternativo e grande/convencional. Ao invés de serem mundos completamente opostos, onde consumidores e produtores seriam independentes uns dos outros, os SAAs seriam mais complexos, ambivalentes, uma vez que suas fronteiras estão em constantes mudanças, bem como as motivações dos atores neles envolvidos.

Nos capítulos 2 e 3, "A promessa de diferença" e "Da ambiguidade do projeto as atividades de regulação”, respectivamente, o autor mobiliza o quadro de análise da sociologia da ação organizada e da sociologia dos agenciamentos mercantis, para discutir a noção de "atividades de regulação" definidas como "atividades que ajudam a construir o coletivo e regular relações dentro dele", as quais podem ser "regras escritas, dispositivos técnicos, discursos, relações estáveis, rotinas e convenções" (p. 26). Além disso, discute a noção de "projeto" visando restaurar o sentido que os atores atribuem à sua ação coletiva e sua capacidade de tomar a iniciativa de mudança.

Considerando o quadro de análise mobilizado, Le Velly propõe refletir acerca 
da "alternatividade" desses sistemas, não porque suas práticas estão realmente rompendo com os sistemas convencionais, mas porque seus projetos são marcados pelo que denomina de "promessa da diferença”, e a define como "a promessa de outra modalidade de organização da produção, das trocas e/ou do consumo alimentar, e a promessa de benefícios associados" (p. 24). É através dela que os atores definem as razões pelas quais é necessário agir e, a partir disso, manifestam a capacidade de projetar e mover-se em favor da criação de alternativas. Nesses capítulos, Le Velly coloca em discussão as diversas "promessas de diferença” presentes no comércio justo - estudado a partir da análise dos casos da Fédération d'Artisans du Monde ${ }^{1}$ e da Max Havelaar France ${ }^{2}$-, e na experiência dos circuitos curtos, tal como essa prática vem sendo organizada pelas AMAPs $^{3}$ (Associação para Manutenção de uma Agricultura Camponesa) na França. Em todas essas situações, o autor verifica uma distância entre o discurso e a atuação prática, o que o leva a questionar a concepção determinista do projeto inicial dessas iniciativas.

Enquanto no Capítulo 2 o autor traz uma discussão que permeia os quadros interpretativos e promocionais das experiências de comércio justo e circuitos curtos, como componentes do projeto coletivo definindo o conteúdo da promessa de diferença, o Capítulo 3 mostra que existe um projeto globalmente partilhado, mas que é marcado por ambiguidades e imprecisões, à exemplo da fixação de preços dentro de uma lógica de custos ou de mercado, em resumo, "os projetos nunca se encaixam totalmente nas práticas" (p. 68).

Le Velly, no Capítulo 4 "O abastecimento local na intersecção de atividades de regulação”, nos ajuda a pensar sobre as atividades de regulação que envolvem esses sistemas, chamando atenção para a regulação alternativa e a convencional. Para isso, o autor apoia-se em três estudos de caso: "Restauration Colletive", nas cidades de Brest e de Nantes, e a experiência do "Restos du Coeur"4 conduzida no Departamento francês do Hérault. Ademais, sugere analisar as compras locais como espaços híbridos, não no sentido de um grande compartilhamento entre circuitos longos e curtos, mas a partir das atividades de regulação que, por sua vez, podem depender das relações de oposição e também das relações de coabitação e relações mais simbióticas, permitindo haver um continuum que varia de nenhum compromisso, para uma cooperação aprofundada, passando por uma coabitação não conflituosa. Assim, o que é híbrido não são os sistemas alimentares, mas as atividades de regulação que permeiam os sistemas alternativos e convencionais.

A partir do caso das "Réseau Artisans du Monde" apresentado no Capítulo 5 "Mu-

1. A Fédération d'Artisans du Monde: é uma rede associativa de origem francesa que trabalha promovendo o comércio justo entre os países do Norte e do Sul, através de ações como: a venda de produtos de comércio justo, educação ao consumidor e campanhas de advocacia para mudar as regras do comércio internacional.

2. A Max Havelaar France: é a principal organização mundial de certificação do comércio justo.

3. As AMAPs: são sistemas de produção e distribuição direta entre o agricultor e o consumidor. Um produtor oferece semanalmente a um conjunto de consumidores membros da associação uma cesta de produtos, sendo que a composição depende da sazonalidade da produção. 
danças de escala e modificações dos agenciamentos mercantis”, o autor demonstra que as atividades de regulação geraram novos agenciamentos mercantis, os quais tornaram possível a mudança de escala dos SAA, vistos através do processo de profissionalização ocorrido no decorrer dos anos. Isso significou uma burocratização das atividades e perdas de muitas características, ao mesmo tempo que levou os consumidores e produtores militantes a novas organizações de mercado e, visando minimizar, por exemplo, a perda da reciprocidade, optou-se por colocar informações sobre a produção e produtor nas embalagens dos alimentos. Ainda, demonstra que a relação com os intermediários não se faz sistematicamente em detrimento da condição do produtor, mas sim do aumento das vendas. Em um segundo caso apresentado, o autor discute a experiência da AMAP Poisson de l'île d'Yeu dando destaque ao "coletivo híbrido”, no qual a agência não é um atributo estritamente humano, pois a capacidade de agenciamento mercantil relaciona-se à sua capacidade de envolver atores humanos e não humanos, conforme propugnado pela teoria do ator-rede. Desse modo, Le Velly constatou que no seio dessas transações estruturadas pelas atividades de regulação convencional há uma hibridação com as atividades de regulação alternativas visando gerar a diferença, pois existem múltiplos dispositivos materiais acionados para tornar viável a comercialização, tal como fretes, contratos, ou mesmo caixas de polietileno, caminhões frigoríficos, necessários ao transporte dos peixes, por exemplo, e exigidos pelas agências de regulação.

Em "O Mainstreaming do comércio justo Fairtrade”, Capítulo 6, Le Velly aponta para um debate acerca da apropriação do comércio justo pelo sistema convencional, tanto nos circuitos de distribuição dos produtos, como na colaboração crescente com esses agentes, argumentando pelo fim do comércio justo como um nicho de mercado. Entretanto, apesar de uma vasta literatura defender a convencionalização do alternativo, o autor chama atenção para uma perspectiva determinista presente nesses trabalhos, que não consideram a trajetória de evolução do comércio justo, gerando confusão quanto aos fenômenos de crescimento comercial e aos fenômenos de evolução da alternatividade. Portanto, para responder a esse debate ele busca identificar as atividades de regulação que permeiam essa mudança no comércio justo, para então analisar como elas estruturam as áreas de ação e, por fim, busca verificar se o que eles fazem afeta ou não as diferentes dimensões da alternatividade. Para isso, discute as consequências das delegações (vendas, operações econômicas e compra) nas atividades de regulação e suas consequências para o projeto de alternatividade, próprias do comércio justo.

Sendo assim, este livro traz outro olhar a respeito dos Sistemas Alimentares Alternativos, mobilizando uma abordagem teórica que dá conta dos limites encontrados nas diversas pesquisas sobre SAA, e nos levando a encarar de forma crítica a alternatividade dos sistemas alimentares, para além de uma abordagem de "convencionalização do alternativo" ou de um "dualismo”. Assim, chamo atenção para a amplitude dos estudos de casos trazidos para ilustrar a tese proposta, o que nos permite enxergar com clareza a promessa de diferença presente nos projetos e suas atividades de regulação. 


\section{Referências}

GOODMAN, D. Agro-food studies in the age of ecology: nature, corporeality, bio-politics. Sociologia Ruralis, v. 39, p.17-38, 1999.

GOODMAN, D. Place and space in alternative food networks: Connecting production and consumption. Department of Geography. King's College London, 2009.

PLOEG, J. van der; RENTING, H.; BRUNORI, G.; KNICKEL, K.; MANNION, J.; MARSDEN, T.; DE ROEST, K.; SEVILLA-GUZMAN, E.; VENTURA, F. Rural Development: From Practices and Policies towards Theory. Sociologia Ruralis, v. 40, n. 4, p. 391-408, 2000.

POMÉON, T., FOUILLEUX, E., LEMEILLEUR; S., LOCONTO, A. L'agriculture biologique en France, entre projet critique et conventionnalisation. In.: ALLAIRE, G., DAVIRON, B. (coord.). Transformations agricoles et agroalimentaires: entre écologie et capitalisme. Versailles: Éditions Quæ, 2017, p. 181-198. 
